\title{
Deep scopulariopsosis: A case report and sensitivity studies
}

\author{
AWATAR S. SEKHON, D. J. WILLANS, AND J. H. HARVEY \\ From the Provincial Laboratory of Public Health, University of Alberta, Edmonton, Alberta, Canada, and \\ Edmonton General Hospital, Edmonton, Alberta, Canada
}

SYNOPSIS A 36-year-old female was admitted to hospital for debridement of chronically inflamed tendon sheaths and adjacent tissues near the left ankle. Despite antibiotic therapy and initial surgical interventions, the inflammation had progressed slowly over 16 months. Histopathological examination of excised tissues in September 1973 revealed a chronic granulomatous inflammation of tendon sheaths and muscle. Many branched hyphal segments, intercalary swollen cells, and a few conidialike bodies were seen in sections, and also in $\mathrm{KOH}$ - and PAS-stained slides prepared from homogenized tissues. Culture of homogenized tissues yielded pure colonies of Scopulariopsis brevicaulis. Sensitivity tests were initially begun with amphotericin B, potassium iodide, and potassium tartrate $(0.05-15 \mu \mathrm{g} / \mathrm{ml}$ of the phytone-yeast extract agar), and no inhibitory effect was observed. Subsequently, amphotericin B, antimony, 5-fluorocytosine (5-FC), griseofulvin, hamycin, and mycostatin were tested $(25-300 \mu \mathrm{g} / \mathrm{ml}$ of the phytone-yeast extract agar). Of these chemicals, griseofulvin and hamycin proved to be most effective. Antimony and 5-FC were ineffective, and mycostatin produced a negligible effect on growth. The four strains of Lysobacter antibioticus, the producer of myxin antibiotic, strongly inhibited the growth of the fungus.

Scopulariopsis brevicaulis (Sacc.) Bainier is a common saprophytic mould, which is known as an occasional cause of toe-nail infections (Morton and Smith, 1963; Padhye and Sekhon, 1973). In contrast, deepseated infections have rarely been described. The first North American report of what was believed to be deep scopulariopsosis, causing ulcerating granulomata of inguinal region in a female, was described by Markley, Philpott, and Weidman (1936) and the organism isolated was $S$. brevicaulis. However, the authors stated that no fungus was demonstrated in the histopathological sections of the granulomata, and their incrimination of $S$. brevicaulis was speculative. Since then there have been no published reports on deep scopulariopsosis. We have recently observed a case of deep scopulariopsosis, and this paper deals with the clinical aspects, histopathological and laboratory investigations, and sensitivity tests on the patient's fungus with the most commonly used antibiotics and a few other compounds.

\section{Received for publication 28 June 1974.}

\section{Case Report}

A 36-year-old woman, living in North-eastern Alberta, injured her left ankle in May 1972. The skin was not broken at the time of injury; however, the ankle became swollen and serous fluid was drained by her physician in her home town. These symptoms recurred despite further incisions and drainage, local steroid injection, and antibiotic therapy which included tetracyclines and ampicillin. She was first seen by one of us (J.H.) approximately two months following the initial injury. A small amount of purulent fluid periodically discharged from the swollen tissues about the ankle (fig 1). The first culture revealed Enterobacter aerogenes. In August 1972, exploration and partial debridement of the soft tissues of the anterior ankle were performed. Excised tissues were submitted for histopathological examination and the sections revealed non-specific acute and chronic tenosynovitis (see histopathology). A plaster walking boot was employed before this initial exploration and for four weeks afterwards. Despite these therapeutic endeavours, combined with further postoperative 


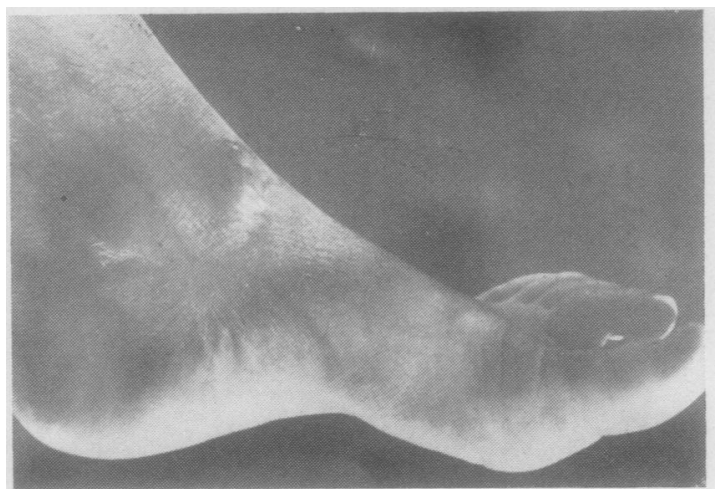

Fig 1 Left ankle showing soft tissue swelling

courses of antibiotics, her symptoms recurred, necessitating further incisions for drainage. The inflammatory response and drainage would periodically subside, sometimes completely, while she was receiving antibiotics only to recur shortly after they were discontinued. In September 1973, 16 months following the initial injury, she again came under our care. A radical debridement was carried out of all inflamed and necrotic tissues, including the tibialis anterior tendon sheath on the anterior aspect of the lower leg and ankle. The inflammatory process did not appear to widely penetrate or communicate through deep fascia planes. The tibialis anterior tendon was partially eroded at its proximal end. Excised tissues and purulent fluids (mycology specimens 4279 and 4280 ) were submitted for histopathological and cultural examinations.

FOLLOW UP

Following the radical debridement of September 1973, the skin was loosely closed and the limb was placed in a below knee cast. Upon receipt of the diagnosis of deep scopulariopsosis, potassium iodide (10 drops/day of saturated solution) was administered for six weeks, pending results of complete sensitivity studies. The patient's leg promptly healed and she had been symptom free for over six months, when last examined in April 1974.

\section{Histopathology}

Examination of initial tissue sections from the debridement of August 1972 revealed non-specific chronic tenosynovitis. The original cell blocks were subsequently retrieved and the periodic-acid-schiff (PAS) and Gomori's methenamine-silver (GMS) stains for fungi were completely negative. The histopathological abnormalities within the excised tissues from the radical debridement of September 1973 contrasted strikingly with the earlier findings. A chronic granulomatous reaction was present which involved subcutaneous tissues, deep fascia, tendon sheath, and skeletal muscle fibres (fig 2). Sheets of confluent, non-caseating granulomata were present; furthermore, these sections revealed the presence of numerous branched, septate hyphae, their fragments, conidia-like bodies, and swollen, thick-walled structures (presumably chlamydospores), which stained better with the GMS technique than PAS and haematoxylin-eosin (H \& E, fig 3).

\section{Direct Microscopic Examination}

Potassium hydroxide ( $\mathrm{KOH}, 30 \% \mathrm{~W} / \mathrm{V}$, aqueous) and PAS smears of ground tissues obtained from the radical debridement of September 1973 showed many branched, septate hyphae, their segments intercalary swollen cells that looked like chlamydo-

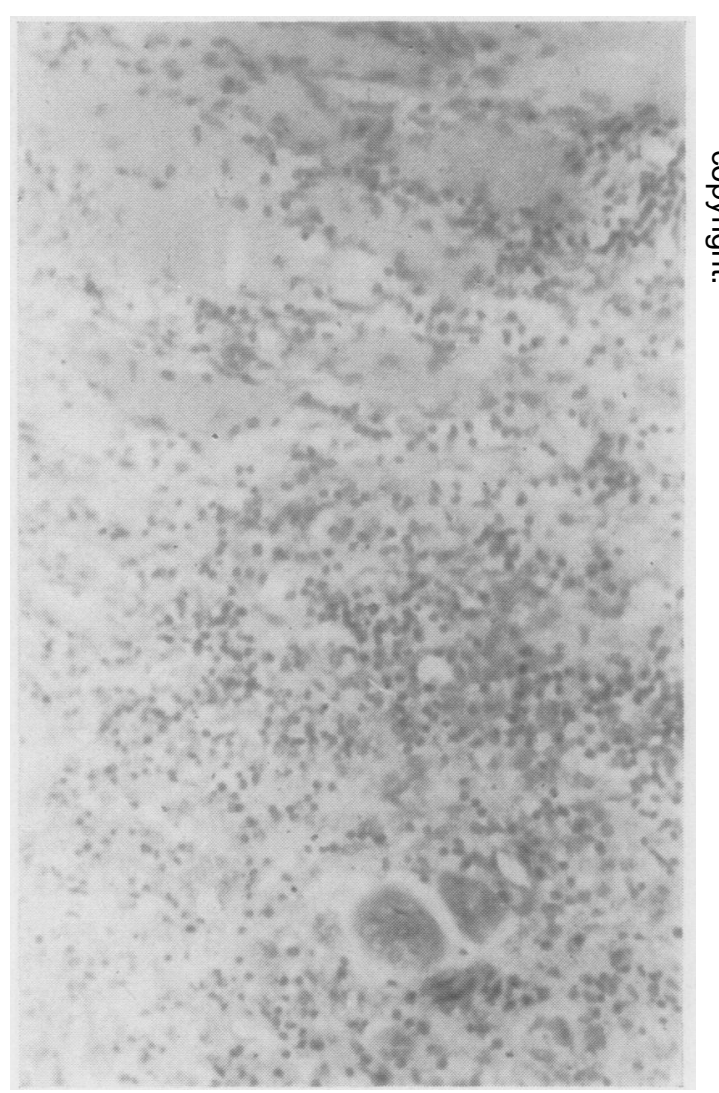

Fig 2 Tissue section showing involvement of skeletal muscle fibres at left $(H \& E) \times 220$ 


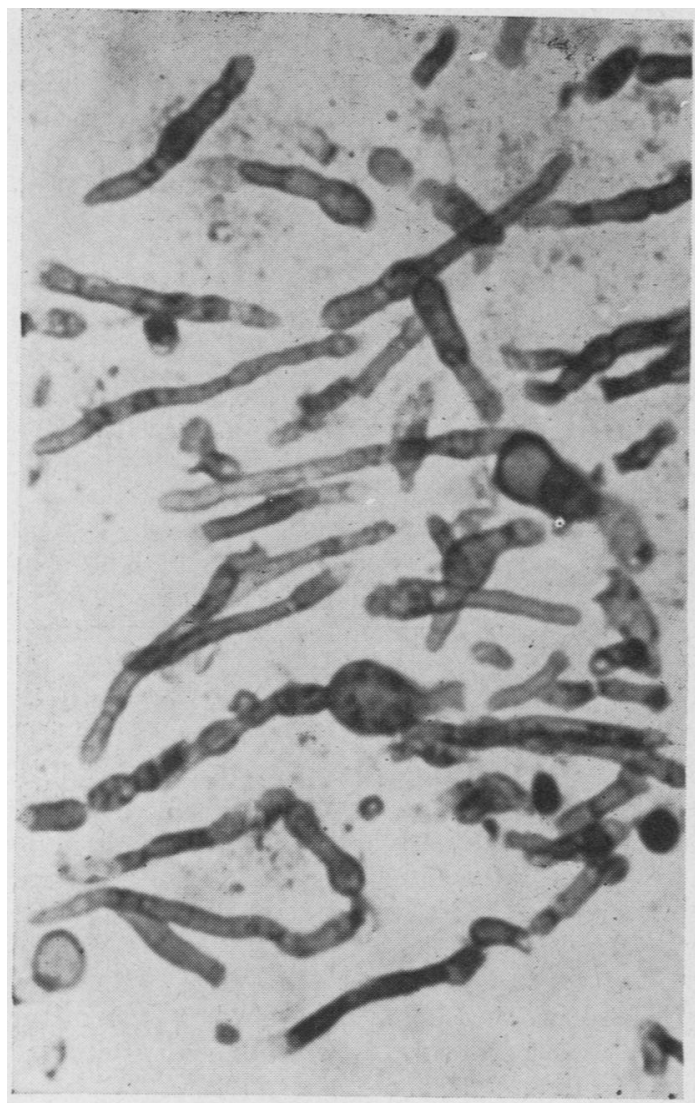

Fig 3 Tissue section showing branched, septate hyphal segments, intercalary swollen cells, and conidia-like bodies $($ GMS $) \times 560$

spores and globose conidia with flat or turncate base (fig 4). The tentative diagnosis at this time was deep scopulariopsosis, and the fungus present in the sections and other smears was identified as Scopulariopsis sp. (brevicaulis?).

\section{Cultural Studies}

Cultures of purulent drainage fluids, before the debridement of August 1972, yielded $E$. aerogenes. Unfortunately, excised tissues from this first debridement (August 1972) were not cultured. Subsequent cultures of purulent drainage fluid yielded a variety of bacteria including $E$. hafnia, Serratia marcescens, and Staphylococcus aureus. No fungus was isolated or reported from these cultures. When the ground tissues of specimens

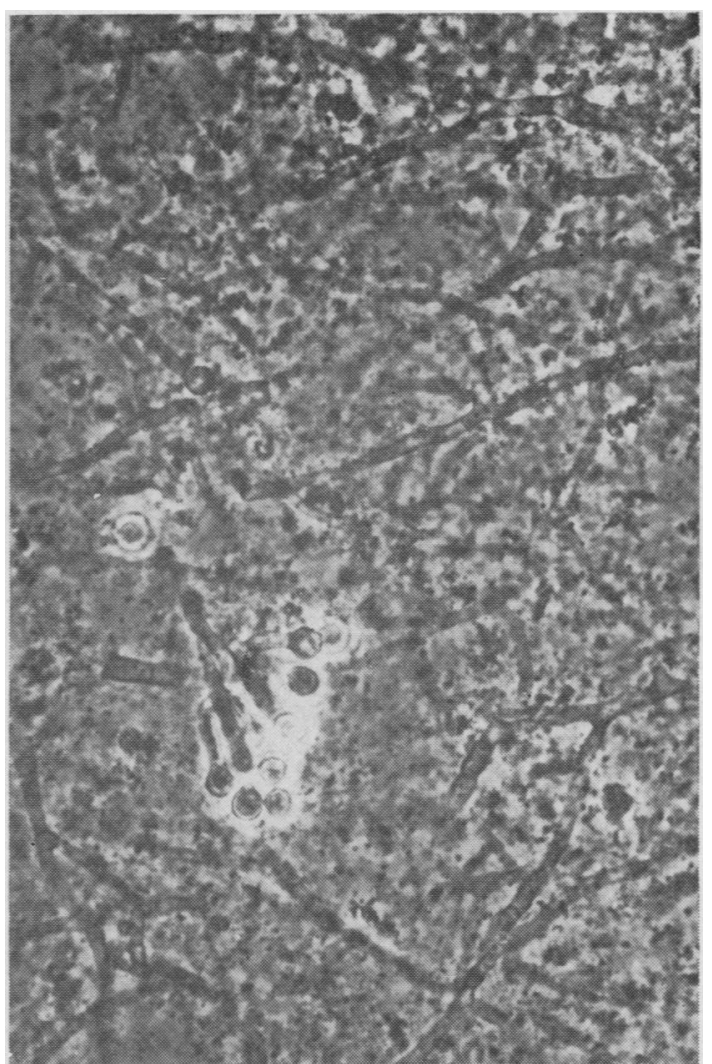

Fig 4 The PAS-stained preparation of specimen 4279 in which numerous branched, septate hyphae, conidiophores bearing rough-walled, globose conidia with flat base are seen $\times 560$.

obtained in September 1973 were plated on the selective mycological and other media (Mycosel and Phytone-yeast extract agars, BBL products; blood agar, Difco) all the plates incubated at 25 and $37^{\circ} \mathrm{C}$ yielded a pure growth of a Scopulariopsis. Cultures of this biopsy material on routine bacteriological media also gave many colonies of Scopulariopsis, and a scant growth of $E$. cloacae.

Slide cultures of the isolates 4279 and $\mathbf{4 2 8 0}$ were made in order to confirm the tentative species identification. The two isolates were indistinguishable in their micromorphology, which showed chains of conidia which were rough walled, globose, and had a truncated base (fig 5).

Colonial morphology of both the isolates was also identical. Colonies were white at the periphery and sand-coloured centrally, and darkened with age. In older cultures (3-5 weeks) white mycelial patches 


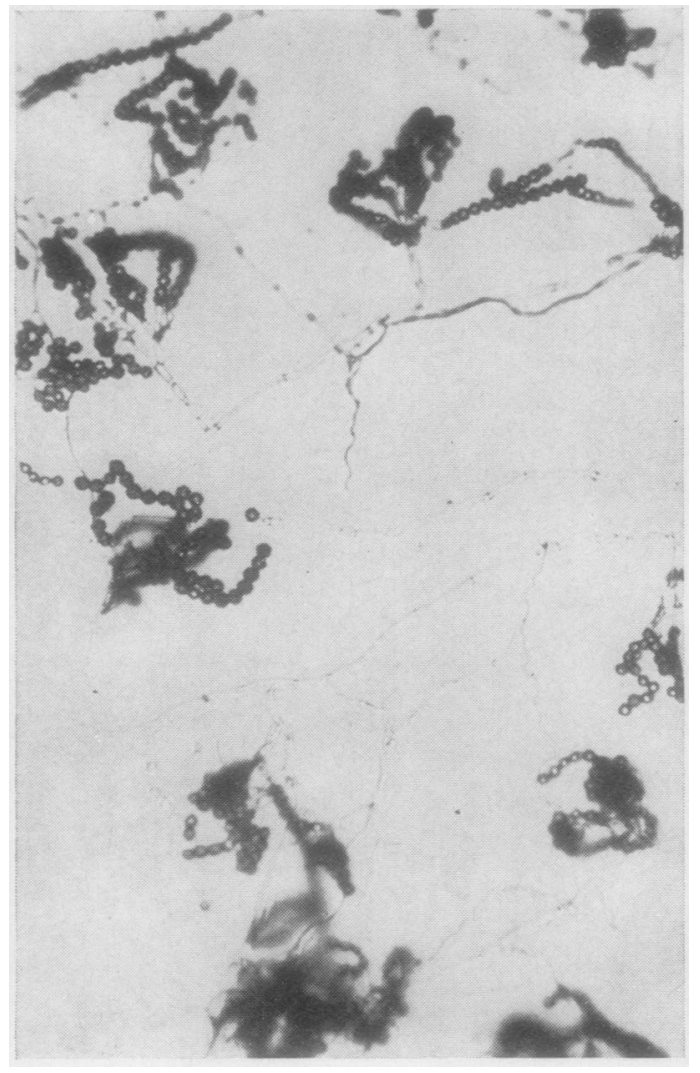

Fig 5 Slide culture of the fungus isolate $4279 \times 220$.

appeared around the inoculum plug. The macroand micromorphologies agreed with the description given by Markley et al (1936) and Morton and Smith (1963); as a result, the fungus was identified as Scopulariopsis brevicaulis. These two isolates have been deposited in Dr J. W. Carmichael's Mold Herbarium and Culture Collection, University of Alberta, and are accessioned as UAMH 3618a and UAMH $3618 \mathrm{~b}$.

\section{Sensitivity Studies}

Sensitivity studies were initially started with amphotericin B (Fungizone), potassium iodide, and potassium tartrate. Amphotericin B was dissolved in sterilized deionized distilled water $(5 \mathrm{mg} / \mathrm{ml})$ following the manufacturer's specification. Stocks of the other two chemicals were made in deionized distilled water and sterilized by suction filtration. The amphotericin B and the above compounds were added into the phytone-yeast extract agar, PYE (phytone-peptone, 10g, BBL; yeast extract, $5 \mathrm{~g}$; dextrose, 40g; agar, $17 \mathrm{~g}$; deionized distilled wateı, 1 litre), held at $50^{\circ} \mathrm{C}$, to obtain $0.05,0.1,0.2,0.5$, $0 \cdot 75,1 \cdot 5,3 \cdot 0,5 \cdot 0,7 \cdot 5,10 \cdot 0$, and $15 \cdot 0 \mu \mathrm{g}$ amounts of each compound per $\mathrm{ml}$ of the medium. Plates after pouring were allowed to stand at $3^{\circ} \mathrm{C}$ for 18 hours and then inoculated at the centre with a disc $(7 \mathrm{~mm}$, diam.) cut from the periphery of a seven-day-old culture grown on Sabouraud dextrose agar (Difco) at $25^{\circ} \mathrm{C}$. Control plates contained PYE and $1 \mathrm{ml}$ of water, which had been used to dissolve the abovementioned compounds. The inoculated plates were incubated at $30^{\circ} \mathrm{C}$ for eight days, when the diameter of the growth was measured in $\mathrm{mm}$. The values for the plates contaiing antibiotic or other compound were then converted into percentage inhibition as compared with control plates. No difference was found between the control and test plates. Further tests were conducted by using amphotericin B, antimony metal, 5-fluorocytosine (5-FC), griseofulvin, hamycin, and mycostatin in the amounts of 25,50 , $75,100,150,200$, and $300 \mu \mathrm{g} / \mathrm{ml}$ of the PYE. All except griseofulvin and hamycin were dissolved in water. These latter antibiotics were dissolved in $\mathbf{N}^{\prime}, \mathbf{N}^{\prime}$, dimethylformamide. Each of these dissolved compounds, except amphotericin B and hamycin, was sterilized by millipore or Seitz filtration. Dilutions of the dissolved hamycin were made in the sterilized deionized distilled water. Procedures for inoculation, growth, and measurements were the same as described above. The inhibitory effect of four strains of Lysobacter antibioticus, the producer of myxin antibiotic, was investigated against both the isolates, using a streak method on tryptone agar (Peterson, Gillespie, and Cook, 1966). This study appeared necessary because these investigators of myxin determined the effectiveness of the drug against a wide variety of bacteria, saprophytic and phytopathogenic fungi, and a few yeasts; but the species of Scopulariopsis were not included.

For each concentration of the compounds used in this study, four replicate plates were used for each isolate. All tests were then repeated, to give a total of 16 plates for each concentration.

\section{Results}

Our first tests with amphotericin B, potassium iodide, and potassium tartrate showed that none of these compounds exerted any inhibitory effect in the concentrations $(0 \cdot 1-15 \mu \mathrm{g} / \mathrm{ml})$ used. In subsequent studies, much higher amounts of amphotericin B and other compounds were used. The results obtained for both isolates were essentially the same, and the values presented in table $I$ are for the isolate 4279. Also, growth responses of these two isolates 


\begin{tabular}{|c|c|c|c|c|c|c|c|c|}
\hline \multirow[t]{3}{*}{ Compound Used } & \multicolumn{8}{|c|}{ Growth Inhibition (\%) } \\
\hline & \multicolumn{8}{|c|}{ Concentration of Compound $(\mu \mathrm{g} / \mathrm{ml}$ of the PYE) } \\
\hline & $\begin{array}{l}0.0 \\
\text { (Control) }\end{array}$ & 25 & 50 & 75 & 100 & 150 & 200 & 300 \\
\hline $\begin{array}{l}\text { Amphotericin B } \\
\text { Antimony metal } \\
\text { 5-Fluorocytosine } \\
\text { Griseofulvin } \\
\text { Hamycin } \\
\text { Mycostatin }\end{array}$ & $\begin{array}{l}\mathrm{Nil} \\
\mathrm{Nil} \\
\mathrm{Nil} \\
\mathrm{Nil} \\
\mathrm{Nil} \\
\mathrm{Nil}\end{array}$ & $\begin{array}{r}17 \cdot 3 \\
-1 \cdot 0 \\
2 \cdot 5 \\
41 \cdot 1 \\
54 \cdot 4 \\
4.6\end{array}$ & $\begin{array}{r}23 \cdot 3 \\
-1 \cdot 0 \\
2 \cdot 3 \\
61 \cdot 0 \\
65 \cdot 1 \\
9 \cdot 5\end{array}$ & $\begin{array}{r}28 \cdot 3 \\
0 \cdot 6 \\
3 \cdot 6 \\
77 \cdot 0 \\
68 \cdot 1\end{array}$ & \begin{tabular}{r|}
34.8 \\
-1.0 \\
1.6 \\
83.2 \\
70.5 \\
11.8
\end{tabular} & \begin{tabular}{r|}
$33 \cdot 8$ \\
-1.0 \\
$4 \cdot 4$ \\
$86 \cdot 2$ \\
$82 \cdot 3$ \\
$14 \cdot 0$
\end{tabular} & $\begin{array}{r}43 \cdot 5 \\
1.0 \\
5 \cdot 0 \\
89 \cdot 4 \\
75 \cdot 0 \\
14 \cdot 7\end{array}$ & $\begin{array}{r}43 \cdot 2 \\
1.0 \\
4.9 \\
89 \cdot 4^{1} \\
80 \cdot 6 \\
16 \cdot 7\end{array}$ \\
\hline
\end{tabular}

Table Results of sensitivity studies with the isolate 4279 of Scopulariopsis brevicaulis

${ }^{1}$ Fungicidal concentration

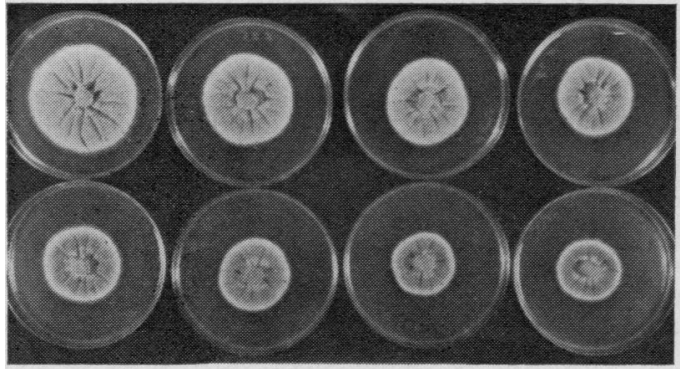

Fig 6a

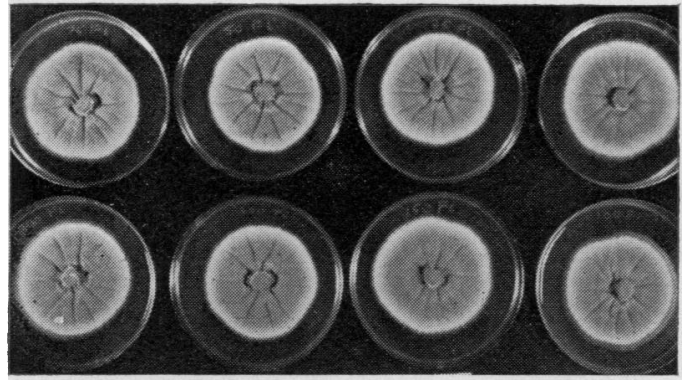

Fig 6b

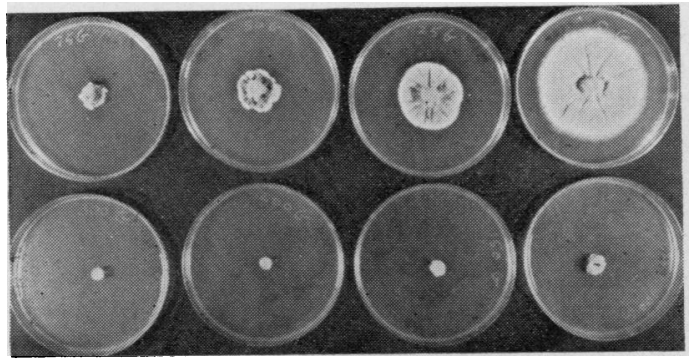

Fig 6c

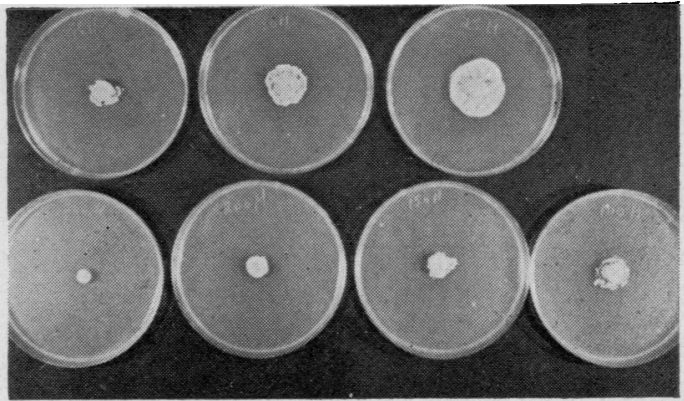

Fig 6d

Fig 6a-e Growth responses of S. brevicaulis 4279 to various concentrations $(0,25,50,75,100,150,200$, and $300 \mu \mathrm{g} / \mathrm{ml}$ of the PYE; from right to left, except amphotericin B) of (a) amphotericin B; left to right; (b) 5-FC; (c) griseofulvin; (d) hamycin; and (e) to the myxinproducing strains of $\mathrm{L}$. antibioticus. Antimony metal and mycostatin gave similar appearances.

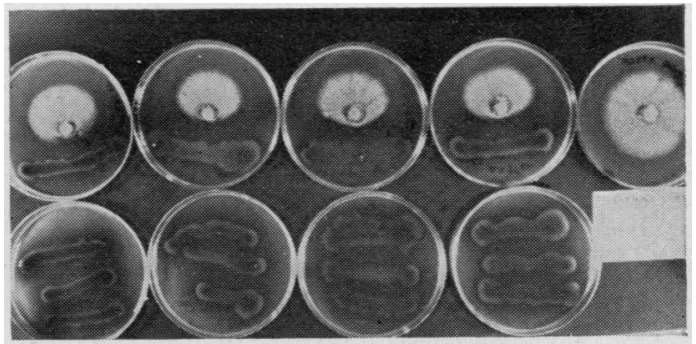

Fig 6e 
were generally identical and fig 6 a-e corresponds to the isolate 4279 . No noticeable differences were observed between repeated tests. Antimony metal had no effect whatsoever on the isolates. 5-Fluorocytosine, mycostatin, and amphotericin B produced very slight to moderate inhibition of growth at the higher concentrations only. Although the effect of amphotericin B was greater than that of 5-FC and mycostatin, the highest concentration $(300 \mu \mathrm{g} / \mathrm{ml}$ of PYE) still produced less than $50 \%$ (ED 50$)$ inhibition (table I and fig 6a). Both griseofulvin and hamycin were found to be very effective even at their lowest levels. Their ED $_{50}$ was approximately 50 and $25 \mu \mathrm{g} / \mathrm{ml}$, respectively. The fungus isolates were found to be very sensitive to the strains of $L$. antibioticus, which was the result of crude antibiotic and/or diffusible metabolite (s) production in the medium (fig 6e).

\section{Discussion}

The present case demonstrates that $S$. brevicaulis is clearly capable of causing chronic granulomatous inflammation of deep soft tissues including skeletal muscle. Such deep involvement in tissue is obviously rare, and to the best of our knowledge this is the first report of a case from Canada. In this presented case, we are uncertain when the $S$. brevicaulis was introduced into the wound, whether during initial injury or more likely inadvertently at a later stage. It emerged as the dominant pathogen many months following the initial injury and initial surgical procedures. The initial tissue sections revealed an acute and chronic tenosynovitis that was typical of bacterial aetiology. The second set of histopathological sections revealed a remarkable change in the inflammatory picture, which was undoubtedly produced by $S$. brevicaulis. Detailed sensitivity studies with the isolates were necessary, because there is no recommended treatment for deep scopulariopsosis; and also because the literature on the sensitivity of this fungus is fragmentary. Significantly, our results indicate that the systemic antifungal antibiotic, amphotericin B, was effective at only very high potentially toxic concentrations. 5-Fluorocytosine, potassium iodide, potassium tartrate, antimony metal, and mycostatin were either proved ineffective or produced little inhibitory effect on growth. The isolates' responses to amphotericin B and 5-FC are rather disappointing, as these are the currently used drugs in virtually deepseated mycoses. Our sensitivity results demonstrated that potassium iodide, potassium tartrate, and antimony metal have no inhibitory effect in vitro on $S$. brevicaulis; however, these compounds in vivo may yield satisfactory results. Mycostatin's useful- ness in deep scopulariopsosis is doubtful indeed, because of the organism's demonstrated poor response to this antibiotic. On the other hand, very promising results were achieved with griseofulvin and hamycin (a systemic antibiotic). Griseofulvin, despite clearly inhibiting the organism in cultures, would not be expected to be of value in deep scopulariopsosis, because its usefulness clinically is apparently related to its deposition within keratinaceous layers of hair, nail, and skin (Korzybski, Kowszyk-Gindifer, and Kurylowicz, 1967; Yu and Blank, 1973), although it has been found to be effective in a case of deep subcutaneous abscesses caused by Trichophyton rubrum (Thorne and Fusaro, 1971). Hamycin has been reported as a successful curative agent in the experimental and natural systemic fungal infections (Padhye and Thirumalachar, 1963; Thirumalachar and Padhye, 1965; Mathias, Kuppuswamy, and Rao, 1964). Preliminary studies in vitro with this drug in Canada (Padhye, 1969; Athar, 1971), and investigations both in vitro and in vivo in the United States (Williams, Bennett, and Emmons, 1964; Pansy, Basch, Jambor, Maestrone, Semar, and Donovick, 1966; Utz, Shadomy, and Shadomy, 1967) have been encouraging. Unfortunately, the drug is not available in Canada for experimental or clinical use. Myxin, like hamycin, proved to be strongly inhibitory, but it also has limited availability for clinical purposes.

We wish to express our sincere thanks to Dr J. M. S. Dixon, Director, Provincial Laboratory of Public Health, Edmonton, Alberta, for his encouragement during the course of this study, and also for his valuable advice and helpful criticism of the manuscript.

We thank Drs J. W. Carmichael, C. H. Jellard, I. W. Geere, J. P. B. Bugeaud, E. H.. Schloss, and G. Goldsand for their suggestions and interest in our work.

The samples of 5-fluorocytosine and hamycin used in this investigation were kindly supplied by Dr J. Y. Gareau, Hoffman LaRoche, Montreal, PQ, and Dr S. B. Sethna, Hindustan Antibiotics Ltd., Pimpri, Poona, India, respectively. The strains of $L$. antibioticus were obtained from Dr. F. D. Cook, Department of Soil Science, University of Alberta, Edmonton, Alberta.

\section{References}

Athar, M. A. (1971). In vitro susceptibility and resistance of Candida spp. to hamycin. Sabouraudia, 9, 256-262.

Korzybski, T., Kowszyk-Gindifer, Z., and Kurylowicz, W. (1967). Antibiotics: Origin, Nature and Properties, Vol. II, pp. 12351248. Pergamon Press, Oxford.

Mathias, P. F., Kuppuswamy, G., and Rao, K. N. A. (1964). Hamycin in the treatment of a case of pulmonary candidiasis. Hindustan antibiot. Bull., 7. 69-73. 
Markley, A. J., Philpott, O. S., and Weidman, F. D. (1936). Deep scopulariopsosis of ulcerating granuloma type confirmed by culture and animal inoculation. Arch. Derm., 33, 627-641.

Morton, F. J. and Smith, G. (1963). The genra Scopulariopsis Bainer, Microascus Zukal, and Doratomyces Corda. Mycological Papers, 86.

Padhye, A. A. (1969). In vitro antifungal activity of hamycin against Histoplasma farciminosum. Mykosen, 12, 203-205.

Padhye, A. A., and Sekhon, A. S. (1973). Dermatophytoses in Alberta (1959-1971). Canad. J. publ. Hlth, 64, 180-184.

Padhye, A. A., and Thirumalachar, M. J. (1963). Hamycin in the treatment of Cryptococcus neoformans in mice. Hindustan antibiot. Bull., 6, 41-43.

Pansy, F. E., Basch, H., Jambor W. P., Maestrone, G., Semar, R., and Donovick, R. (1966). Hamycin: In vitro and in vivo studies. Antimicrob. Agents and Chemother., 1965, pp. 399-404.

Peterson, E. A., Gillespie, D. C., and Cook, F. D. (1966). A wide- spectrum antibiotic produced by a species of Sorangium. Canad. J. Microbiol., 12, 221-230.

Thirumalachar, M. J., and Padhye, A. A. (1965). Experimental blastomycosis treated orally with hamycin. Sabouraudia, 4, 6-10.

Thorne, E., and Fusaro, R. (1971). Subcutaneous Trichophyton rubrum abscesses: a case report. Dermatologica (Basel), 142, 167-170.

Utz, J. P., Shadomy, H. J., and Shadomy, S. (1968). Clinical and laboratory studies of a new micronized preparation of hamycin in systemic mycoses in man. Antimicrob. Agents and Chemother., 1967, pp. 113-117.

Williams, T. W., Jr., Bennett, J. E., and Emmons, C. W. (1964). Chemotherapeutic and toxic activity of hamycin in experimental mycoses. Antimicrob. Agents and Chemother., 1963, pp. 737-741.

Yu, R. J., and Blank, F. (1973). On the mechanism of action of griseofulvin in dermatophytosis. Sabouraudia, 11, 274-278.

\section{The September 1974 Issue}

\section{THE SEPTEMBER 1974 ISSUE CONTAINS THE FOLLOWING PAPERS}

Interaction of gelatin with stereospecific binding proteins and its enhancement of competitive binding aSSAYS BEVERLEY E. PEARSON MURPHY AND MAVIS MARVIN

The problem of the demonstration of hepatitis $B$ antigen in faeces and bile J. W. MOODIE, LINDA $M$. STANNARD, AND A. KIPPS

A light and electron microscopic study of the liver in a case of erythrohepatic protoporphyria and in griseofulvin-induced prophyria in mice A. MATILLA AND ELIZABETH A. MOLLAND

Necropsy studies on adult coeliac disease $\mathrm{H}$. THOMPSON

Antibodies to Candida albicans in hospital patients with and without spinal injury and in normal men and women P. H. EVERALL, C. A. MORRIS, AND DELIA F. MORRIS

Sensitivity of Citrobacter freundii and Citrobacter koseii to cephalosporins and penicillins B. HOLMES, ANNA KING, I. PHILlIPS, AND S. P. LAPAGE
The nitroblue tetrazolium (NBT) test in renal transplantation A. M. GORDON, J. D. BRIGGS, AND P. R. F. BELL

Comparison of the diagnostic value of bone marrow biopsy and bone marrow aspiration in neoplastic disease JAMES D. BEARDEN, GARY A. RATKIN, AND CHARLES A. COLTMAN

Separation of abnormal cells in the peripheral blood by means of the zonal centrifuge PATRICIA M. EGAN AND J. V. GARRETT with an appendix by C. W. GILBERT

Collimation and surface counting in haematology C. S. BOWRING AND H. I. GLASS

Automated quality control for the haematology laboratory I. CAVILL AND C. RICKETTS

Tests of disinfection by heat in a bedpan washing machine G. A. J. AYLIFFE, B. J. COLLINS, AND C. E. A. DEVERILL

\section{Technical method}

The isolation and identification of Vibrio cholerae A. L. FURNISS AND T. J. DONOVAN

Book reviews

Copies are still available and may be obtained from the PUBLISHING MANAGER, BRITISH MEDICAL ASSOCIATION, TAVISTOCK SQUARE, LONDON, WClH 9JR, price $£ 1.05$. 